\title{
O discurso político-criminal sobre o crime organizado no Brasil
}

\section{The discourse of the criminal policy on organized crime in Brazil}

\author{
CARLO VelHo MASI ${ }^{1}$ \\ Advogado criminal em Porto Alegre, RS
}

\begin{abstract}
RESUMO: O presente estudo visa a analisar o fenômeno da criminalidade organizada, inserida no contexto da globalização, e as recentes alterações político-criminais no que tange ao tratamento das novas modalidades delitivas no Brasil. Apresentase um panorama da complexificação do crime e das dificuldades definitoriais a ela inerentes, especialmente em relação à definição de organização criminosa para fins de conferir segurança jurídica mínima ao sistema penal. Mais adiante, demonstra-se que a realidade do contexto regional impõe-se como um limite à incorporação irrefletida de modelos de repressão ao crime organizado. Por fim, a pesquisa analisa que a historicidade própria do fenômeno criminal impede uma conceituação estanque de organização criminosa e que, conquanto a crítica global não seja razoável, não é possível perder a capacidade de análise isenta, no caso concreto, das reais possibilidades que legitimam a disciplina.
\end{abstract}

Palavras-chave: Globalização. Crime Organizado. Organizações Criminosas. Política Criminal.

ABSTRACT: This study aims to analyze the organized crime phenomenon within the context of globalization and the recent political changes regarding the treatment of the new criminal modalities in Brazil. It is presented an overview of the complexity of crime and the difficulties in its definition, especially regarding the concept of criminal organization for providing a minimum legal certainty to the penal system. Further on, it is shown that the reality of the regional context is imposed as a limit to the thoughtless incorporation of models of repression to the organized crime. Finally, the research analyzes that the historicity of the criminal phenomenon prevents a stagnant conceptualization of criminal organization and that, while the global critics is not reasonable, it is not possible to lose the ability of a exempt analysis in the specific case of the real possibilities that legitimate the discipline.

Keywords: Globalization. Organized Crime. Criminal Organizations. Criminal Policy.

\section{INTRODUÇÃO: A GLOBALIZAÇÃO E O DIREITO PENAL}

A globalização define os modelos sociais pósindustriais e é hoje uma chave para a compreensão da criminalidade $^{2}$. Suas potencialidades permitem que os grupos criminosos aproveitem as vantagens que o novo espaço mundial oferece, com a criação de zonas de livre comércio em algumas regiões do mundo, nas quais se produz uma permeabilização econômica das fronteiras nacionais e se reduz o controle.

Esta mudança é identificada por Zaffaroni, quando se refere às atuais orientações de Polícia Criminal ${ }^{3}$. A realidade do poder planetário é demasiadamente contraditória em comparação a momentos anteriores. $\mathrm{O}$ que antes foram delitos contra a economia nacional, como alterações artificiais dos mercados, aproveitamento de informações confidenciais, monopólios e oligopólios, e até mesmo delitos menos sofisticados, como extorsões e fraudes, agora são condutas legítimas na economia mundial. Ante a ausência de um poder regulador e criminalizante no plano internacional, trata-se de condutas impunes, com a particularidade de que se cometem em proporções macroeconômicas. Impõe-se a precisa conclusão a que chega Alberto Silva Franco:

A inexistência de um Estado mundial ou de organismos internacionais suficientemente fortes que disponham do ius puniendi e que possam, portanto, emitir normas penais de caráter supranacional, a carência de órgãos com legitimação para o exercício do ius persequendi e a falta de concretização de tribunais penais internacionais agravam ainda mais as dificuldades do enfrentamento dessa criminalidade gerada pela globalização. Além disso, o Estado-nação, derruído na sua soberania e tornado mínimo pelo poder econômico global, não tem condições de oferecer respostas concretas e rápidas aos crimes dos poderosos, em relação aos quais há, no momento, um clima que se avizinha à anomia ${ }^{4}$. 
Fala-se, então, em "crimes antiglobalização", na medida em que determinadas tipificações impedem o natural avanço das instituições capitalistas que pregam a autorregulação do Mercado 5 .

Surge um comércio de bens e serviços ilegais que coexiste com o mercado legal, onde o crime adquire uma enorme capacidade de diversificação, organizando-se estrutural e economicamente para explorar campos tão diferentes quanto o jogo, o proxenetismo (lenocínio), a pedofilia, o tráfico de pessoas, drogas, armas, veículos ou o furto de obras de arte.

O abandono do controle cambial, com a dinamização das trocas cambiárias; a abertura dos sistemas financeiros, em razão das conversões cambiais livres; o aumento da competitividade internacional, facilitando a aceitação dos agentes de transações pouco discretas; e a informatização do sistema são reformas financeiras que determinaram o aumento da complexidade das práticas ilícitas a partir da década de 90 do séc. $\mathrm{XX}^{6}$, com a lavagem de capitais ${ }^{7}$ aparecendo como complemento natural e necessário dessas atividades ${ }^{8}$.

A criminalidade associada aos meios informáticos e à Internet (a chamada "ciber delinquência") é seguramente o maior exemplo dessa evolução. Nesta medida, é plenamente verificável a vinculação do progresso técnico com o desenvolvimento de novas formas de criminalidade organizada ${ }^{9}$.

Os fenômenos da globalização e da integração econômica geraram a aparição de uma nova concepção do delito, centrada particularmente nos elementos organização, transnacionalidade e poder econômico, completamente distintos da ideia de delinquência como fenômeno "marginal".

Do ponto de vista estrutural, as características mais significativas da criminalidade da globalização são duas: por um lado, trata-se de uma criminalidade, em sentido amplo, organizada (a produzir resultados lesivos capazes de aparecer em separado, tanto no espaço, como no tempo, da ação dos sujeitos mais relevantes do plano delitivo); de outro, seus crimes são criminologicamente categorizados como "crimes dos poderosos" (crimes of the powerfull), em contraposição aos crimes do Direito Penal clássico (crimes of the powerless) ${ }^{10}$. É uma criminalidade de sujeitos influentes, configurada pela magnitude dos seus efeitos - normalmente econômicos, mas também políticos e sociais -, que ultrapassam fronteiras (internacionalização ${ }^{11}$ ) e têm capacidade de desestabilização (lesividade) geral dos mercados e corrupção de funcionários e governantes ${ }^{12}$.

A nova criminalidade distingue-se, também, pela impossibilidade de sua referência a uma pessoa ou a uma coisa individual, sendo completamente imaterial. Os interesses da sociedade contemporânea remetem irrevogavelmente à tutela dos denominados bens jurídicos supra e transindividuais, sociais, comunitários, universais ou coletivos ${ }^{13}$, direcionando a proteção às empresas, ao mercado, à segurança social, financeira, fiscal, ao meio ambiente, dentre outros, com contornos imateriais e imprecisos, que passam a demandar, para a sua tutela, um modus operandi diferenciado, máxime diante das dificuldades que suas características ensejam na delimitação da causalidade e do dano ${ }^{14}$.

Um tipo de criminalidade que permite a separação tempo-espaço entre a ação das pessoas que atuam no plano criminoso e a danosidade social. Tal criminalidade, desvinculada do espaço geográfico fechado de um Estado, espraia-se por vários outros e distancia-se nitidamente dos padrões de criminalidade que até então tinham sido objeto de consideração penal ${ }^{15}$.

Sua presença na economia limita a liberdade de acesso e a oportunidade de novos investimentos e de consumo, além de alterar o funcionamento do mercado, da propriedade e do trabalho, o que acaba prejudicando o saudável desenvolvimento econômico ${ }^{16}$.

É frequente a prática do "branqueamento" de capitais, pois os benefícios obtidos com as atividades delitivas precisam ser "reciclados", isto é, despojados de sua origem criminosa, mediante sua introdução nos circuitos financeiros lícitos, até conseguir uma aparência de legalidade ${ }^{17}$.

As técnicas e os procedimentos de lavagem de capitais demandam sofisticação, no sentido de poderem elidir a ação dos países que os combatem, cambiando e evoluindo continuamente, à medida que os organismos encarregados de sua repressão vão identificando e neutralizando as vias já existentes. Esse profissionalismo se justifica no sentido de minimizar os riscos da persecução penal e maximizar as oportunidades.

Por essas razões, a incriminação dos mecanismos pelos quais as organizações criminosas ${ }^{18}$ conseguem ocultar e investir consideráveis somas de dinheiro obtidas por meio de suas atividades figura hoje entre os mais atuais e problemáticos temas do Direito Penal contemporâneo ${ }^{19}$.

\section{A COMPLEXIFICAÇÃO DO CRIME}

A moderna criminalidade empresarial pode ser caracterizada por um tipo de delito motivado altruisticamente. Enquanto na concepção tradicional o autor do fato criminoso quer beneficiar a si mesmo ou a alguém relativamente próximo a si, razão pela qual atua de forma interesseira ou egoística, na criminalidade econômica o perfil de autoria é totalmente distinto. $\mathrm{O}$ 
agente não quer mais (apenas) enriquecer ou beneficiar a si mesmo ou a uma pessoa que lhe é próxima; ele aspira uma vantagem para a empresa ${ }^{20}$, para a instituição ou organização criminosa a qual pertence.

As descrições dos delitos do moderno Direito Penal são orientadas pela criminalidade absolutamente sem vítimas (crimes without victims) ou com vítimas rarefeitas $^{21}$. Não se exige mais dano comparável com a modificação do mundo exterior (crimes de dano), mas apenas a falta de cumprimento de uma tarefa imposta pelo Estado no caso concreto (crimes de perigo) ${ }^{22}$. O injusto nada mais é do que o resultado de uma pura avaliação técnica ${ }^{23}$. Por isso, Prittwitz explica que a periculosidade desta nova criminalidade advém não de uma conduta praticada isoladamente, mas de sua reiteração ("efeito de acumulação"), que provoca consequências com perspectivas temporais muito mais amplas $^{24}$.

No combate à criminalidade econômica, por exemplo, via regra está em jogo a punição de uma omissão. Uma lesão aos deveres de fiscalização, organização, informação e vigilância (compliance) comumente ocorre porque estes não são cumpridos de maneira suficiente. Com isso, se a omissão se converte em categoria primária da responsabilidade penal, colocam-se questões absolutamente novas sobre o conteúdo do conceito de ação e sobre a relação entre o agir e o omitir ${ }^{25}$.

Cabe frisar que a moderna criminalidade organizada não está necessariamente vinculada à criminalidade econômica. Porém, existe uma imbricação, já que, na maioria das vezes, uma organização criminosa atua na comissão dos delitos econômicos ${ }^{26}$, pois, via de regra, no âmbito das sociedades empresárias, a associação de várias pessoas terá finalidade lícita prevista e autorizada em lei ${ }^{27}$.

Assim, no contexto do chamado "processo penal de emergência"28, em que várias garantias processuais são mitigadas, em prol do "combate" a essas novas práticas criminosas ${ }^{29}$, já não é mais possível confrontar as demandas com instrumentos da dogmática penal clássica, de origem liberal-iluminista ${ }^{30}$.

\section{A CRIMINALIDADE ORGANIZADA E AS DIFICULDADES DEFINITORIAIS DAS ORGANIZAÇÕES CRIMINOSAS}

A criminalidade organizada geralmente diz respeito à reunião de vários membros de uma sociedade, que se associam e organizam sua atividade criminal como um projeto empresarial, formando o que se denomina de organização criminosa. Precisa é, então, a constatação de Laura Zúñiga Rodrígues, para quem há muito poucos acordos sobre o que se entende por criminalidade organizada. As diversas perspectivas com que tem sido tradada demonstram que é um fenômeno multiforme, complexo e sumamente cambiante que, portanto, é difícil de apreender em concepções teóricas e, ainda mais, em leis penais ${ }^{31}$.

Em linhas gerais, organização criminosa pode ser descrita como uma entidade coletiva ordenada em função de estritos critérios de racionalidade em que cada um de seus membros realiza uma determinada função, para qual se encontra especialmente capacitado, em razão de suas aptidões ou possibilidades pessoais. Assim agindo, a organização alcança características próprias de uma sociedade de profissionais do crime, na qual se manifesta um sistema de relações específicas, definidas a partir de obrigações e privilégios recíprocos.

Nessa linha, o conceito de crime organizado parece cumprir relevantes funções de legitimação do poder, especialmente nas áreas da polícia (ampliando o poder capaz de mobilizar maiores recursos materiais e humanos), da justiça (conferindo-lhe mais eficiência, mediante redução de complicações legais) e da política em geral (oferecendo aos políticos um tema de campanha capaz de produzir votos, aos partidos políticos a oportunidade de competirem entre si pela melhor estratégia contra o crime organizado e ao poder político o discurso sobre a ameaça real desse novo inimigo interno da democracia, capaz de justificar restrições aos princípios da legalidade, da culpabilidade e de outras garantias do devido processo legal no Estado Democrático de Direito) ${ }^{32}$.

Revela-se, pois, um discurso encobridor da incapacidade política de reformas democráticas dos governos locais. A incompetência política em face de problemas comunitários estruturais de emprego, habitação, escolarização, saúde etc., seria compensada pela demonstração de competência administrativa na luta contra o crime organizado.

Há muito, o Brasil tem tentado esboçar um conceito legislativo de organização criminosa que seja válido para todo o sistema e possa reduzir a insegurança jurídica no tratamento do tema. Por longo período, as referências às organizações criminosas dispostas na hoje revogada Lei $\mathrm{n}^{\mathrm{0}}$ 9.034/95 $5^{33}$ foram complementadas, inclusive para fins de tipificação pelo delito de lavagem de capitais ${ }^{34}$, por entendimento pretoriano, pelo conceito de "grupo criminoso organizado", fornecido pela Convenção das Nações Unidas contra o Crime Organizado Transnacional ("Convenção de Palermo") 35 .

O advento da Lei $\mathrm{n}^{\mathrm{o}}$ 12.694/12, que instituiu o julgamento colegiado em primeiro grau de jurisdição para crimes praticados por organizações criminosas, não resolveu suficientemente a questão, pois esboçou 
um conceito válido tão-somente para efeitos daquela legislação, que hoje já se encontra obsoleto ${ }^{36}$.

Atualmente, parece que, em função de revogação tácita ${ }^{37}$, sobrepõe-se o conceito ventilado pela recente Lei $n^{-} 12.850 / 13$, segundo a qual

Considera-se organização criminosa a associação de 4 (quatro) ou mais pessoas estruturalmente ordenada e caracterizada pela divisão de tarefas, ainda que informalmente, com objetivo de obter, direta ou indiretamente, vantagem de qualquer natureza, mediante a prática de infrações penais cujas penas máximas sejam superiores a 4 (quatro) anos, ou que sejam de caráter transnacional.

A propósito, os méritos deste novo diploma legislativo ainda estão por ser melhor analisados em espaço próprio, na medida em que disciplina diversos procedimentos investigativos, inserindo, definitivamente, o Brasil no cenário internacional de repressão ao crime organizado, inclusive com expressa referência às infrações penais previstas em tratado ou convenção internacional quando, iniciada a execução no País, o resultado tenha ou devesse ter ocorrido no estrangeiro, ou reciprocamente; e às infrações penais praticadas por organizações que ultrapassam as fronteiras territoriais brasileiras ${ }^{38}$, reconhecidas segundo normas de Direito Internacional.

Além de tipificar o crime de "promover, constituir, financiar ou integrar, pessoalmente ou por interposta pessoa, organização criminosa", a Lei no 12.850/13 prevê como meios de obtenção de prova a colaboração premiada; a captação ambiental de sinais eletromagnéticos, ópticos ou acústicos; a ação controlada; o acesso a registros de ligações telefônicas e telemáticas, a dados cadastrais constantes de bancos de dados públicos ou privados e a informações eleitorais ou comerciais; a interceptação de comunicações telefônicas e telemáticas, nos termos da legislação específica; o afastamento dos sigilos financeiro, bancário e fiscal, nos termos da legislação específica; a infiltração, por policiais, em atividade de investigação, na forma do art. 11; e a cooperação entre instituições e órgãos federais, distritais, estaduais e municipais na busca de provas e informações de interesse da investigação ou da instrução criminal.

Ainda, dentre outras importantes alterações, a mencionada lei tipifica crimes ocorridos na investigação e na obtenção da prova e faz uma paradigmática alteração na redação e nomenclatura do antigo delito de quadrilha ou banco (art. 288 do Código Penal), que passa a se chamar "associação criminosa" e tipificar a conduta de "Associarem-se 3 (três) ou mais pessoas, para o fim específico de cometer crimes".
Essas medidas, aliadas às recentes alterações da Lei de Lavagem de Capitais, promovidas pela Lei no $12.683 / 12$ - principalmente a revogação do rol de crimes antecedentes, tornando passível a incriminação da ocultação ou dissimulação de bens direitos ou valores provenientes, direta ou indiretamente, de infração penal (legislação de $3^{\underline{a}}$ geração) -, e pelas alterações que a Lei $\mathrm{n}^{\mathrm{O}}$ 12.694/12 promoveram no Código Penal e no Código de Processo Penal - no que se refere à possibilidade de decretação da perda de bens ou valores equivalentes ao produto ou proveito do crime quando estes não forem encontrados (isto é, quando não forem produto direto do crime) ou quando se localizarem no exterior e quanto à possibilidade de alienação antecipada de bens para preservação de seu valor sempre que estiverem sujeitos a qualquer grau de deterioração ou depreciação, ou quando houver dificuldade para sua manutenção - aproximam o país um pouco mais da realidade.

Nada obstante a discussão político-criminal retomada com a nova lei das organizações criminosas, em termos acadêmicos prevalece a controvérsia. É que organização criminosa não se trata de um conceito jurídico, e sim criminológico, para o qual seria impossível esgotar todas as manifestações dos grupos ilícitos organizados numa única definição rígida e atempora ${ }^{39}$. Como já exposto, o fenômeno da criminalidade organizada está em constante mudança, de acordos com as novas tecnologias que, a cada dia, são incorporadas ao espaço negocial, tudo visando ao maior lucro possível, com a redução máxima dos riscos.

Por isso, Zaffaroni define o conceito como uma "categoria frustrada", ou seja, um rótulo sem utilidade científica, carente de conteúdo jurídico-penal ou criminológico. A definição legal de crime organizado seria desnecessária, porque não designaria nada que já não estivesse contido no conceito de quadrilha ou bando (hoje associação criminosa), um tipo de crime contra a paz pública, previsto em qualquer Código Penal.

$\mathrm{Na}$ verdade, os fenômenos atribuídos ao crime organizado seriam explicáveis pela própria dinâmica do mercado, através da constante criação de novas áreas de produção, circulação e consumo ainda não disciplinadas pela lei (por exemplo, os jogos eletrônicos, o mercado da droga, etc.), ocupadas imediatamente por múltiplas empresas do mercado, cujo espectro de atividades seria constituído por ações legais e ações ilegais que, no limite, são insuscetíveis de separação entre $\mathrm{si}^{40}$.

La mundialización ha llegado, como no podía ser de otra forma, al ámbito de la criminalidad, y la delincuencia organizada se ha desarrollado 
estructuralmente con modernos criterios empresariales, adoptando en muchos casos formas de gestión, de implantación y extensión en los diferentes Estados muy similar a las técnicas empleadas por las mismas multinacionales ${ }^{41}$.

\section{O CONTEXTO REGIONAL COMO LIMITE À INCORPORAÇÃO DE MODELOS DE REPRESSÃO AO CRIME ORGANIZADO}

A delinquência organizada sempre existiu paralelamente à atividade lícita organizada, ambas em função da tendência do homem de planejar suas tarefas, sobretudo quando trabalha em grupo. Porém, nas sociedades contemporâneas, a delinquência organizada em sentido específico, ou qualitativamente organizada (em oposição à delinquência de baixo grau de organização, inerente, de alguma forma, a qualquer classe de delinquência coletiva ou associação delitiva), alcançou dimensões extremamente vastas ${ }^{42}$.

Existem dois modelos de crime organizado hoje predominantes no mundo: aquele estruturado no polo americano e europeu do sistema capitalista globalizado, definido como conspiração nacional de etnias estrangeiras; e aquele discurso italiano sobre crimine organizzato, que tem por objeto de estudo original a máfia siciliana ${ }^{43}$.

O discurso americano de organized crime, originário das instituições de controle social, nasce com a série de programas econômicos que ficaram conhecidos como new deal, do governo de Franklin Roosevelt, entre 1933 e 1936, com o objetivo de estigmatizar grupos sociais étnicos (especialmente italianos), sob o argumento de que o comportamento criminoso não seria uma característica da comunidade americana, mas de um submundo constituído por estrangeiros, aqueles maus cidadãos que ameaçavam destruir a comunidade dos bons cidadãos.

Esse conceito xenófobo revelou sua utilidade, através de teorias criminológicas fundadas na noção de subcultura e desorganização social, definindo o crime organizado como conspiração contra o povo e contra o governo americanos, promovida por organizações nacionais secretas, centralizadas e hierarquizadas de grupos étnicos estrangeiros.

Tal discurso foi imediatamente assumido por políticos e difundido pelos meios de comunicação de massa para justificar campanhas de lei e ordem, eficazes como estratégias eleitorais de candidatos ao Congresso e à Presidência da República. Extinto o mercado ilícito e os lucros fabulosos da criminalização do álcool durante a chamada "lei seca", o perigo atribuído ao organized crime deslocou o eixo para o tráfico de drogas, um novo mercado ilícito com lucros fabulosos criados pela política de criminalização das drogas, promovida a nível planetário pelo governo americano, sob o mesmo paradigma da conspiração contra o american way of life, agora com conexões internacionais.

Ocorre que a própria Criminologia americana sustenta que o conceito de crime organizado é um mito. As atividades criminosas atribuídas ao crime organizado teriam sido realizadas, em realidade, por grupos locais desarticulados, sem a organização estrutural da conspiração difundida pelo controle social, por políticos e pela mídia americanos. Assim, novamente segundo Zaffaroni, "trata-se de um pseudoconceito, inventado pelo jornalismo e pelos políticos da primeira metade do século passado" 44 .

Por outro lado, as organizações italianas de tipo mafioso, originalmente dirigidas à repressão de camponeses em luta contra o latifúndio e que teriam evoluído para empreendimentos urbanos, atuando na área da construção civil, do contrabando e da extorsão sobre o comércio e a indústria, assumiram progressivamente características financeiro-empresariais, com empresas no mercado legal e a inserção no circuito financeiro internacional para lavagem do dinheiro do tráfico de drogas.

Essas organizações são estruturas de poder informal constituídas para proteger a realização de objetivos de lucro, geralmente mediante intermediação parasitária das relações entre capital e trabalho (por exemplo, os sindicatos), entre produção e consumo (por exemplo, as redes de distribuição) ou entre Estado e cidadão (por exemplo, os contratos para obras públicas).

O discurso criminológico italiano é útil para mostrar que organizações de tipo mafioso - ou seja, de estruturas dotadas de organização empresarial definíveis como quadrilhas ou bandos - não seriam produtos anômalos das sociedades capitalistas, nem fenômenos patológicos de sociedades intrinsecamente saudáveis, mas produtos orgânicos do ecossistema social, expressões de desenvolvimento econômico defeituoso, ou excrescências parasitárias danosas à comunidade e à organização democrática da vida.

Seja como for, Juarez Cirino dos Santos adverte que o discurso italiano sobre a máfia não pode, simplesmente, ser transferido para outros contextos nacionais - como o do Brasil -, sem uma grave distorção conceitual ou deformação do objeto de estudo. Sucede que os limites de validade do discurso da criminologia italiana sobre organizações de tipo mafioso são fixados pela área dos dados da pesquisa científica respectiva, e qualquer discurso sobre fatos atribuíveis a organizações 
de tipo mafioso em outros países precisa ser validado por pesquisas científicas próprias ${ }^{45}$.

Essas redes detêm um grande poder baseado numa estrutura organizada que permite aproveitar as fragilidades estruturais do sistema penal, provocando grandes danos sociais. Dispõem de meios instrumentais e de moderna tecnologia, com um intrincado esquema de conexões com outros grupos criminosos e uma rede subterrânea de ligações com os quadros oficiais da vida social, econômica e política da comunidade. Das organizações criminosas, originam-se atos de extrema violência, que expõem um poder de corrupção de difícil visibilidade pelo uso de disfarces e simulações.

Luis Flávio Gomes identifica determinados atributos comuns que revelariam a existência de uma associação ilícita organizada: hierarquia estrutural; planejamento empresarial; uso de meios tecnológicos avançados; recrutamento de pessoas; divisão funcional das atividades; conexão estrutural ou funcional com o poder público ou com agentes do poder público; oferta de prestações sociais ${ }^{46}$; divisão territorial das atividades ilícitas; alto poder de intimidação ${ }^{47}$; alta capacitação para a prática de fraudes ${ }^{48}$; e conexão local, regional, nacional ou internacional com outras organizações criminosas. $\mathrm{O}$ autor sugere que três desses atributos seriam suficientes para qualificar como organizada qualquer associação ilícita ${ }^{49}$.

A infração criminal cometida pelas organizações criminosas não se esgota em si mesma, pois despojase de autonomia, para passar a ser um elemento a mais de um programa preestabelecido que se prolonga indefinidamente no tempo. Estabelece-se uma hierarquia que subordina as intervenções de cada um, mas, no marco da operação como um todo, a garantia do sucesso está justamente na organização e confiança nos integrantes do grupo.

As modernas estruturas criminais não atuam de forma isolada; as organizações criminais estruturamse através de coordenação e subordinação, favorecendo o estabelecimento das chamadas "redes corporativas de associações criminais", que, dentre seus objetivos, prestam apoio logístico mútuo.

Há, inclusive, quem repute imprescindível para a caracterização de uma criminalidade dita organizada a conivência de um agente público ou político que facilite ou ordene a atividade criminosa, sem a qual esta tornar-se-ia impossível de ser realizada de maneira estruturada ${ }^{50}$.

A resposta penal contra o chamado crime organizado tende a dirigir-se a um maior rigor repressivo, com a introdução de novas modalidades de prisões cautelares, instituição de "prêmio" ao acusado colaborador, criação de programas de proteção de testemunhas, inaugurando o assim denominado duplo binário repressivo (Código Penal para os crimes comuns e leis especiais para essa nova criminalidade) $)^{51}$.

No Brasil, especificamente, a Política Criminal "oficial" contra o crime organizado foi responsável pela introdução de diversos institutos ou mecanismos lesivos dos fundamentos constitucionais do Direito Penal e do Processo Penal, como a figura do agente infiltrado em quadrilhas ou organizações e/ou associações criminosas ${ }^{52}$; a delação premial como negociação para extinguir ou reduzir a punibilidade de crimes por informações sobre coautores ou partícipes de fatos criminosos, localização da vítima e recuperação do produto do crime $^{53}$; a supressão da liberdade provisória ${ }^{54}$ e do direito de apelar em liberdade ${ }^{55}$; a instituição do regime fechado obrigatório no início do cumprimento da pena ${ }^{56}$; e, finalmente, a quebra do sigilo das comunicações pela captação e interceptação de sinais eletromagnéticos, óticos e acústicos ${ }^{57}$. É bem verdade que, com a revogação da lei $\mathrm{n}^{\circ} 9.034 / 95$, algumas incorreções flagrantes estão sendo revistas.

Esses mecanismos, sem o controle judicial adequado e utilizados de maneira indiscriminada demonstram a fragilidade da adoção de discursos pré-fabricados em relação ao crime organizado. Se é certo que o Brasil lida hoje com o crime organizado, deve-se verificar se as mesmas técnicas de tutela utilizadas em outros países pode ser legitimamente implantada no sistema pátrio. É crucial lembrar, neste ponto, que há países que, inclusive, admitem a flexibilização de direitos humanos básicos (permitindo, exemplificativamente, a tortura) quando se trata de apurar ações de grupos criminosos, muitas vezes automaticamente rotulados de "terroristas".

\section{CONSIDERAÇÕES FINAIS: A INVIABILIDADE DA CONCEITUAÇÃO ESTÁTICA DAS ORGANIZAÇÕES CRIMINOSAS}

Deve-se assinalar que o tipo de delitos praticados pelas organizações criminosas evoluiu com o Direito Penal para os novos âmbitos de incriminação. Porém, condutas delitivas clássicas, como furto, roubo, apropriação indébita, estelionato e tráfico em geral, permanecem sendo as principais, agora com o incremento de técnicas e tecnologias extremamente sofisticadas (v.g. clonagem de cartões de crédito, criação de softwares para obtenção de senhas eletrônicas, oferta de produtos inexistentes em sites de compra, venda de produtos proibidos no mercado negro - Black Market - na deepweb, etc.), que 
aumentam de maneira incalculável o potencial lesivo dessas práticas.

Na sociedade da mundialização, com as modernas tecnologias, aumenta-se consideravelmente o potencial leviso de outras condutas delitivas conhecidas tradicionalmente. Pode-se levar a cabo uma campanha de difamação contra um cidadão honrado. Grupos que pretendem incitar o ódio, a violência e a discriminação de outros sujeitos, seja por razões étnicas, nacionais ou religiosas, aproveitam-se da capacidade de propagação da rede mundial de computadores para criar um caldo de cultivo hostil e perigoso para aqueles que se identificam como "diferentes".

Conviver com o "outro", neste cenário, é exacerbar os riscos a que estamos passíveis. Transmitem-se vídeos com pretensões sádicas de desfrute do usuário que os contemple, cenas reais de tortura e mortes cruéis de pessoas e animais. Utilizam-se menores para a elaboração de filmes pornográficos, incluindo tomadas sadomasoquistas. Distintos grupos terroristas e grupos armados de todo o Planeta trocam informações sobre estratégias e informações para levar a cabo os mais sórdidos atentados contra a humanidade, utilizando mecanismos de comunicação modernos próprios das novas tecnologias ${ }^{58}$.

Produzem-se, então, comportamentos antes impensáveis, por inexistentes. A internet passou a ser a principal ferramenta de delinquentes altamente especializados, conhecidos como hackers e crackers, que atuam valendo-se do anonimato que as vias de comunicação do espaço cibernético proporcionam, praticando condutas lesivas, tais como bullying, stalking, phishing, spamming, pedofilia, pirataria, etc., muitas delas identificadas como "crimes virtuais" ou "crimes cibernéticos", que, por vezes, não possuem qualquer interesse econômico envolvido.

A dificuldade em lidar preventivamente com essas práticas está na própria indeterminação do sujeito ativo. Até mesmo Estados, sem que se possa identificar o autor mediato, ou "homem de trás" (hinterman) ${ }^{59}$ podem praticar violações criminosas de direitos fundamentais e de direitos de outras nações. O caso mais notório da atualidade é a denúncia de espionagem que autoridades brasileiras sofreram por parte da NSA (National Security Agency), órgão de inteligência dos EUA.

Logo, o Direito Penal vê-se obrigado a lidar com essas novas condutas e definitivamente não poderá combatê-las com as mesmas "armas" do séc. XVIII, que, se serviram ao enfrentamento dos delitos clássicos, lesivos diretamente ao ser humano e ao patrimônio, hoje demonstram sua fragilidade. O contexto reclama uma reinterpretação da dogmática jurídico-penal clássica, a fim de determinar quais parâmetros permanecem válidos, quais estão irremediavelmente superados pelas práticas sociais e quais ainda valem a pena ser preservados e, se for o caso, defendidos com rigidez. Isso implica afastar a postura de crítica integral ao moderno desenvolvimento do Direito Penal, sem, contudo, perder a capacidade de análise isenta, no caso concreto, das reais possibilidades que legitimam a disciplina. Não se pode perder de vista, sobretudo, uma análise conforme à Constituição.

Sendo assim, acreditamos que uma conceituação estática de organização criminosa, tal como a pretendida pelo legislador brasileiro, está fadada a representar mais um casuísmo simbólico momentâneo, que será em breve sufragado pelo próprio historicismo inerente ao natural desenvolvimento do fenômeno criminal. No Brasil, embora as pontuais reformas representem, em certa medida, alguma espécie de avanço, apenas uma reestruturação global (é dizer, novo Código Penal e novo Código de Processo Penal) será capaz de dar novas luzes ao enfrentamento do tema.

\section{REFERÊNCIAS}

ALBRECHT, Peter-Alexis. Kriminologie. Munique: C.H. Beck, 1999.

BITENCOURT, Cezar Roberto. Organização criminosa: não se aplica a majorante em lavagem de dinheiro. Disponível em: $<$ http:// www.conjur.com.br/2013-ago-26/cezar-bitencourt-nao-aplicamajorante-crime-lavagem-dinheiro>. Acesso em: 26 ago. 2013.

BONFIM, Márcia Monassi Mougenot; GARCIA, Gilberto Leme Marcos; LEMOS JÚNIOR, Arthur Pinto de. Doutrina e tratado define organização criminosa. Disponível em: $<$ http://www.conjur. com.br/2009-nov-26/conceito-organizacao-criminosa-definidotipificar-lavagem>. Acesso em: 11 abr. 2013.

BORJA JIMÉNEZ, Emiliano. Globalización y concepciones del derecho penal. Estudios Penales y Criminológicos, Santiago de Compostela, Espanha, USC, n. 29, p. 141-206, 2009.

BUONICORE, Bruno Tadeu. Breves reflexões criminológicas sobre os delitos empresariais. Revista Síntese Direito Penal e Processual Penal, Porto Alegre, Sìntese, v. 13, n. 75, p. 77-80, ago./set. 2012.

CALLEGARI, André Luís. Direito penal econômico e lavagem de dinheiro: aspectos criminológicos. Porto Alegre: Livraria do Advogado, 2003.

CERQUEIRA, Átilo Antonio. Direito penal garantista \& A nova criminalidade. Curitiba: Juruá, 2002.

CHOUKR, Fauzi Hassan. Processo penal de emergência. Rio de Janeiro: Lumen Juris, 2001.

COSTA JR., Paulo José da. Crimes do colarinho branco: comentários à lei n. 7.492/86, com jurisprudência; aspectos de direito constitucional e financeiro e anotações à lei n. 9.613/98, que incrimina a "lavagem de dinheiro". 2. ed. São Paulo: Saraiva, 2002. ESTELLITA, Heloisa. Criminalidade de empresa, quadrilha e organização criminosa. Porto Alegre: Livraria do Advogado, 2009.

FIGUEIREDO DIAS, Jorge de. Para uma dogmática do direito penal secundário. In: D’AVILA, Fábio Roberto; SPORLEDER, Paulo Vinícius. Direito penal secundário. São Paulo: Revista dos Tribunais, 2006. 
FRANCO, Alberto Silva. Globalização e Criminalidade dos Poderosos. In: PODVAL, Roberto (Org.). Temas de direito penal econômico. São Paulo: Revista dos Tribunais, 2000.

GOMES, Luiz Flavio; CERVINI, Raúl. Crime organizado: enfoques criminológico, jurídico (Lei 9.034/95) e político-criminal. 2. ed. rev. atual. e ampl São Paulo: Revista dos Tribunais, 1997.

HASSEMER, Winfried. Características e Crises do Moderno Direito Penal. Revista Sintese de Direito Penal e Processual Penal. Porto Alegre, ano III, n. 18, p. 144-157, fev/mar. 2003.

HERRERO, César Herrero. Criminologia. Parte general y especial. Madrid: Dykinson, 1997.

JORNAL ESTADO DE SÃO PAULO. Maior investigação da história do crime organizado denuncia 175 do PCC. Disponível em: $<$ http://www.estadao.com.br/noticias/cidades,maior-investigacaoda-historia-do-crime-organizado-denuncia-175-do-pcc,1084346,0. htm>. Acesso em 16 out. 2013.

MASI, Carlo Velho. O crime de evasão de divisas na era da globalização. Porto Alegre: Pradense, 2013.

NAÏM, Moisés. O ilicito. Trad. Sérgio Lopes. Rio de Janeiro: Zahar, 2006.

PRITTWITZ, Cornelius. Sociedad de riesgo y Derecho penal. In: ZAPATERO, Luis Arroyo; NEUMANN, Ulfrid; MARTÍN, Adán Nieto. (Coord.). Critica y justificacion del derecho penal en el cambio de siglo: el análisis crítico de la escuela de Frankfurt. Cuenca, Espanha: Ediciones de la Universidad de Castilla-La Mancha, 2003. p. 259-287.

RINALDI, Stanislau. Crime organizado e poder politico na Itália In Anais do III Congresso Nacional do Movimento do Ministério Público Democrático, Foz do Iguaçu, PR, 18-21 de março de 1997.

RODRIGUES, Anabela Miranda; MOTA, José Luís Lopes da. Para uma política criminal europeia: quadro e instrumentos jurídicos da cooperação judiciária em matéria penal no espaço da União Europeia. Coimbra: Coimbra Editora, 2002.
ROTSCH, Thomas. Tempos Modernos: Ortodoxia e Heterodoxia no Direito Penal. In: D'AVILA, Fabio Roberto (Org.). Direito Penal e Política Criminal no Terceiro Milênio: Perspectivas e Tendências. Porto Alegre: EDIPUCRS, 2011. p. 68-81.

ROXIN, Claus. La ciencia del derecho penal ante las tareas del futuro. In: MUÑOZ CONDE, Francisco (Coord.). La Ciencia del Derecho penal ante le Nuevo Milenio. Valencia: Tirant lo Blanch, 2004

SCHUR, Edwin M. Crimes without Victims: Deviant Behavior and Public Policy Abortion, Homosexuality, Drug Addiction. Englewood Cliffs, NJ, EUA: Prentice-Hall, 1965.

SILVA SÁNCHEZ, Jesús-María. La expansión del derecho penal. Aspectos de la política criminal en las sociedades postindustriales. Madrid: Civitas, 1999

SILVA, Luciana Carneiro da. Perspectivas Político-criminais sob o Paradigma da Sociedade Mundial do Risco. Revista Liberdades, São Paulo, IBCCRIM, n. 5, p. 85-115, set./dez. 2010.

SILVEIRA, Renato de Mello Jorge. Direito Penal econômico como Direito Penal de perigo. São Paulo: Revista dos Tribunais, 2006.

ZAFFARONI, Eugenio Raúl. Crime Organizado: uma categorização frustrada. Discursos Sediciosos: Crime Direito e Sociedade, Rio de Janeiro, v. 1, n. 1, p. 45-67, jan./jun. 1996.

ZAFFARONI, Eugenio Raúl. Globalización y crimen organizado. Conferência proferida na "Primera Conferencia Mundial de Derecho Penal" (AIDP) em 22 de novembro de 2007 em Guadalajara, Jalisco, México.

ZAFFARONI, Eugenio Raúl. La Globalización y las Actuales Orientaciones de la Política Criminal. Direito e Cidadania, Praia, Cabo Verde, a. 3, n. 8, p. 71-96, 1999-2000.

ZAFFARONI, Eugenio Raúl. O inimigo no Direito Penal. Rio de Janeiro: Revan, 2007.

ZÚÑIGA RODRÍGUEZ, Laura. Criminalidad organizada, derecho penal y sociedad. Apuntes para el análiseis. In: SANZ MULAS, Nieves (coord.). El desafio de la criminalidade organizada. Granada: Comares, 2006.

\section{NOTAS}

1 Bacharel em Direito pela PUCRS. Especialista em Direito Penal e Política Criminal pela UFRGS. Mestre em Ciências Criminais pela PUCRS. Associado ao Instituto Brasileiro de Ciências Criminais (IBCCRIM), Instituto Brasileiro de Direito Processual Penal (IBRASPP) e Instituto Brasileiro de Direito Penal Econômico (IBDPE)

2 RODRIGUES, Anabela Miranda; MOTA, José Luís Lopes da. Para uma política criminal europeia: quadro e instrumentos jurídicos da cooperação judiciária em matéria penal no espaço da União Europeia. Coimbra: Coimbra Editora, 2002, p. 13.

3 ZAFFARONI, Eugenio Raúl. La Globalización y las actuales orientaciones de la política criminal. Direito e Cidadania, Praia, Cabo Verde, a. 3, n. 8, p. 71-96, 1999-2000, p. 79.

4 FRANCO, Alberto Silva. Globalização e Criminalidade dos Poderosos. In: PODVAL, Roberto (Org.). Temas de direito penal econômico. São Paulo: Revista dos Tribunais, 2000, p. 257.

5 MASI, Carlo Velho. O Crime de Evasão de Divisas na Era da Globalização. Porto Alegre: Pradense, 2013, p. 130.

6 NAÏM, Moisés. $O$ ilícito. Trad. Sérgio Lopes. Rio de Janeiro: Zahar, 2006, p. 129-130.

7 Como bem recorda CALLEGARI, André Luís. Direito penal econômico e lavagem de dinheiro: aspectos criminológicos. Porto Alegre: Livraria do Advogado, 2003, p. 91, "além de afetar as relações interpessoais e o patrimônio individual, a delinquência organizada e os processos de lavagem de dinheiro possuem objetivos e finalidades especiais, distintos da criminalidade tradicional, desenvolvendo em grande escala e com espírito empresarial uma série de macro atuações, algumas de caráter supranacional, que terminam por influenciar de maneira importante o próprio sistema econômico".
8 RODRIGUES, Anabela Miranda; MOTA, José Luís Lopes da. Para uma política criminal europeia: quadro e instrumentos jurídicos da cooperação judiciária em matéria penal no espaço da União Europeia. Coimbra: Coimbra Editora, 2002, p. 14.

9 SILVA SÁNCHEZ, Jesús-María. La expansión del Derecho Penal: aspectos de la política criminal em las sociedades postindustriales. 2. ed. Madrid: Civitas, 2001. p. 28.

10 RODRIGUES, Anabela Miranda; MOTA, José Luís Lopes da. Para uma politica criminal europeia: quadro e instrumentos jurídicos da cooperação judiciária em matéria penal no espaço da União Europeia. Coimbra: Coimbra Editora, 2002, p. 14.

11 RODRIGUES, Anabela Miranda; MOTA, José Luís Lopes da. Para uma política criminal europeia: quadro e instrumentos jurídicos da cooperação judiciária em matéria penal no espaço da União Europeia. Coimbra: Coimbra Editora, 2002, p. 13.

12 SILVA SÁNCHEZ, Jesús-María. La expansión del derecho penal Aspectos de la política criminal en las sociedades postindustriales. Madrid: Civitas, 1999, p. 69-71.

13 No sentido de que existem até mesmo bens jurídicos supranacionais, que exigem uma tutela também supranacional: ROXIN, Claus. La ciencia de derecho penal ante las tareas del futuro. In: MUÑOZ CONDE, Francisco (Coord.). La Ciencia del Derecho penal ante el Nuevo Milenio. Valencia: TirantloBlanch, 2004, p. 401-406.

14 SILVA, Luciana Carneiro da. Perspectivas Político-criminais sob o Paradigma da Sociedade Mundial do Risco. Revista Liberdades, São Paulo, IBCCRIM, n. 5, p. 85-115, set./dez. 2010, p. 100-101.

15 FRANCO, Alberto Silva. Globalização e criminalidade dos poderosos. In: PODVAL, Roberto (Org.). Temas de direito penal econômico. São Paulo: Revista dos Tribunais, 2000, p. 257. 
16 CALLEGARI, André Luís. Direito penal econômico e lavagem de dinheiro: aspectos criminológicos. Porto Alegre: Livraria do Advogado, 2003, p. 91 observa que "Além de afetar as relações interpessoais e o patrimônio individual, a delinquência organizada e os processos de lavagem de dinheiro possuem objetivos e finalidades especiais, distintos da criminalidade tradicional, desenvolvendo em grande escala e com espírito empresarial uma série de macro atuações, algumas de caráter supranacional, que terminam por influenciar de maneira importante o próprio sistema econômico",

17 CALlEGARI, André Luís. Direito penal econômico e lavagem de dinheiro: aspectos criminológicos. Porto Alegre: Livraria do Advogado, 2003, p. 38

18 SILVEIRA, Renato de Mello Jorge. Direito Penal econômico como Direito Penal de perigo. São Paulo: Revista dos Tribunais, 2006, p. 58 relata que "com origens remotas nas velhas familias criminosas, mafiosas, de origens italiana, japonesa, como a Yacuza, chinesa, como as tríades, ou, ainda, russa, após a queda do velho império, o crime organizado é, na atualidade, fenomeno que bem reflete a quebra das fronteiras nacionais. Em periodo anterior os vários ramos ou famílias cingiam suas atividades a áreas bem especificas. Hoje não. Transformaram-se elas em um tema que abala as próprias estabilidades econômicas, politicas e sociais de vários países."

19 CERQUEIRA, Átilo Antonio. Direito penal garantista \& A nova criminalidade. Curitiba: Juruá, 2002 realiza uma reflexão sobre aos delineamentos da "nova criminalidade" no cenário nacional no contexto do "Direito penal fernandino" (conjunto de leis penais especiais produzidas durante dos governos de Fernando Collor de Mello e Fernando Henrique Cardoso), da violência decorrente de suas práticas e dos complexos mecanismos exigidos a seu imprescindível controle, bem como da distinção com a criminalidade "tradicional" ou "massificada".

20 ROTSCH, Thomas. Tempos Modernos: Ortodoxia e Heterodoxia no Direito Penal. In: D’AVILA, Fabio Roberto (org.). Direito Penal e Política Criminal no Terceiro Milênio: Perspectivas e Tendências. Porto Alegre: EDIPUCRS, 2011. p. 68-81, p. 77.

${ }^{21}$ SCHUR, Edwin M. Crimes without Victims: Deviant Behavior and Public Policy Abortion, Homosexuality, Drug Addiction. Englewood Cliffs, NJ, EUA: Prentice-Hall, 1965.

22 FIGUEIREDO DIAS, Jorge de. Para uma dogmática do direito penal secundário. In: D’AVILA, Fábio Roberto; SPORLEDER, Paulo Vinícius. Direito penal secundário. São Paulo: Revista dos Tribunais, 2006, p. 42 43.

23 HASSEMER, Winfried. Características e Crises do Moderno Direito Penal. Revista Sintese de Direito Penal e Processual Penal. Porto Alegre, ano III, n. 18, p. 144-157, fev./mar. 2003, p. 151.

24 PRITTWITZ, Cornelius. Sociedad de riesgo y Derecho penal. In: ZAPATERO, Luis Arroyo; NEUMANN, Ulfrid; MARTÍN, Adán Nieto. (Coord.). Critica y Justificacion del Derecho Penal en el cambio de siglo: el análisis crítico de la escuela de Frankfurt. Cuenca, Espanha: Ediciones de la Universidad de Castilla-La Mancha, 2003. p. 259-287, p. 261 ss.

25 ROTSCH, Thomas. Tempos Modernos: Ortodoxia e Heterodoxia no Direito Penal. In: D’AVILA, Fabio Roberto (org.). Direito Penal e Politica Criminal no Terceiro Milênio: Perspectivas e Tendências. Porto Alegre: EDIPUCRS, 2011. p. 68-81, p. 76.

${ }^{26}$ CALLEGARI, André Luís. Direito penal econômico e lavagem de dinheiro: aspectos criminológicos. Porto Alegre: Livraria do Advogado, 2003, p. 27

27 Veja-se o caput do art. 966 do Código Civil brasileiro: "Considerase empresário quem exerce profissionalmente atividade econômica organizada para a produção ou a circulação de bens ou de serviços.'

28 Ideia que está atrelada à de urgência (e, num certo sentido, à de crise), a algo que, de forma repentina, surge de modo a desestabilizar o status quo ante e os padrões normais de comportamento e possibilidade de manutenção das estruturas. Ademais, a expressão se atrela à necessidade de uma resposta pronta e imediata, que deve durar enquanto o estado emergencial perdura (CHOUKR, Fauzi Hassan. Processo penal de emergência. Rio de Janeiro: Lumen Juris, 2001, p. 1-2).

${ }^{29}$ COSTA JR., Paulo José da. Crimes do colarinho branco: comentários à lei n. 7.492/86, com jurisprudência; aspectos de direito constitucional e financeiro e anotações à lei n. 9.613/98, que incrimina a "lavagem de dinheiro". 2. ed. São Paulo: Saraiva, 2002, p. 184.

30 BUONICORE, Bruno Tadeu. Breves Reflexões Criminológicas sobre os Delitos Empresariais. Revista Síntese Direito Penal e Processual Penal. Porto Alegre, Síntese, v. 13, n. 75, p. 77-80, ago./set. 2012, p. 77.

31 ZÚÑIGA RODRÍGUEZ, Laura. Criminalidad organizada, derecho penal y sociedad. Apuntes para el análiseis. In: SANZ MULAS, Nieves (coord.). El desafio de la criminalidade organizada. Granada: Comares, 2006, p. 39-68.
32 ALBRECHT, Peter-Alexis. Kriminologie. Munique: C.H. Beck, 1999 p. $385-386$

33 Que dispunha sobre a utilização de meios operacionais para a prevenção e repressão de ações praticadas por organizações criminosas.

34 Art. 1ํ, VII (hoje revogado), da Lei no 9.613/98.

35 Promulgada pelo Decreto no 5.015/2004. "Artigo 2. Para efeitos da presente Convenção, entende-se por: a) Grupo criminoso organizado" - grupo estruturado de três ou mais pessoas, existente há algum tempo e atuando concertadamente com o propósito de cometer uma ou mais infrações graves ou enunciadas na presente Convenção, com a intenção de obter, direta ou indiretamente, um benefício econômico ou outro benefício material".

36 Art. 2º, Lei no 12.694/2012 - "Para os efeitos desta Lei, considerase organização criminosa a associação, de 3 (três) ou mais pessoas, estruturalmente ordenada e caracterizada pela divisão de tarefas, ainda que informalmente, com objetivo de obter, direta ou indiretamente, vantagem de qualquer natureza, mediante a prática de crimes cuja pena máxima seja igual ou superior a 4 (quatro) anos ou que sejam de caráter transnacional".

37 BITENCOURT, Cezar Roberto. Organização Criminosa: Não se aplica a majorante em lavagem de dinheiro. Disponível em: $<$ http://www.conjur. com.br/2013-ago-26/cezar-bitencourt-nao-aplica-majorante-crimelavagem-dinheiro>. Acesso em: 26 ago. 2013.

38 Vejamos o caso da famosa organização denominada Primeiro Comando da Capital (PCC), cujas investigações determinaram que possui "braços" em outros países da América do Sul, como Paraguai e Bolívia. (JORNAL ESTADO DE SÃO PAULO. Maior investigação da história do crime organizado denuncia 175 do PCC. Disponível em: <http://www.estadao. com.br/noticias/cidades, maior-investigacao-da-historia-do-crimeorganizado-denuncia-175-do-pcc,1084346,0.htm>. Acesso em 16 out. 2013.

39 ESTELLITA, Heloisa. Criminalidade de empresa, quadrilha e organização criminosa. Porto Alegre: Livraria do Advogado, 2009 No mesmo sentido: BONFIM, Márcia MonassiMougenot; GARCIA, Gilberto Leme Marcos; LEMOS JÚNIOR, Arthur Pinto de. Doutrina e tratado define organização criminosa. Disponível em: <http://www. conjur.com.br/2009-nov-26/conceito-organizacao-criminosa-definidotipificar-lavagem>. Acesso em: 11 abr. 2013.

40 ZAFFARONI, Eugenio Raúl. Crime Organizado: uma categorização frustrada. Discursos Sediciosos: Crime Direito e Sociedade, Rio de Janeiro, v. 1, n. 1, p. 45-67, jan./jun. 1996.

41 ZAFFARONI, Eugenio Raúl.Globalización y crimen organizado. Conferência proferida na "Primera Conferencia Mundial de Derecho Penal" (AIDP) em 22 de novembro de 2007 em Guadalajara, Jalisco, México.

${ }^{42}$ HERRERO, César Herrero. Criminologia: Parte general y especial Madrid: Dykinson, 1997, p. 475

43 PALESTRA intitulada "Crime Organizado", proferida no 1ํㅡón Latino-Americano de Política Criminal, promovido pelo IBCCRIM, de 14 a 17 de maio de 2002, em Ribeirão Preto, SP.

44 ZAFFARONI, Eugenio Raúl. O inimigo no Direito Penal. Rio de Janeiro: Revan, 2007, p. 63

45 PALESTRA intitulada "Crime Organizado", proferida no $1^{\text {o }}$ Fórum Latino-Americano de Política Criminal, promovido pelo IBCCRIM, de 14 a 17 de maio de 2002, em Ribeirão Preto, SP.

46 Às vezes, como decorrência lógica da conexão estrutural ou funcional com o Poder Público, outras vezes como forma de se buscar algum tipo de "legitimação popular" para o crime organizado, pode-se constatar nessa atividade ilícita o "clientelismo", que consiste em oferecer "prestações sociais" no âmbito da saúde pública, da segurança, dos transportes, alimentação, moradia, emprego certo, etc. Busca-se, pela tutela das camadas mais carentes, um certo apoio popular e, ao mesmo tempo, a substituição do Estado oficial. Desse modo, cria-se um Estado "paralelo", que passa a ser visto como "necessário", principalmente naqueles lugares onde não chegam as prestações públicas oficiais.

47 A capacidade de intimidação e subordinação caracteriza o método mafioso, por excelência, o qual tende a produzir impunidade, medo e silêncio, resultando na existência de códigos internos de conduta, da aplicação de sanções extralegais, de julgamentos secretos e peremptórios, da violência ostensiva, etc.

48 Essa é a vertente do "crime organizado do colarinho branco" (criminalidade dourada), de pouca visibilidade ou ostentação, isto é, escasso crime appeal. Por isso, do conceito de crime organizado pode também fazer parte a real capacidade de lesar o patrimônio público ou coletivo por meios fraudulentos (fraude difusa), capacidade essa derivada exatamente da associação complexa e organizada, da sofisticação dos 
recursos tecnológicos empregados, da conexão com os poderes públicos, da eventual participação de agentes públicos, da possibilidade de amplo acesso que conquistam as agências públicas, etc.

49 GOMES, Luiz Flavio; CERVINI, Raúl. Crime organizado: enfoques criminológico, jurídico (Lei 9.034/95) e político-criminal. 2. ed. rev., atual. e ampl. São Paulo: Revista dos Tribunais, 1997, p. 99-100.

50 PALESTRA intitulada "Crime Organizado e sua Difícil Conceituação", proferida por Fabio Leandro Rods Ferreira no "I Simpósio de Direito: As alterações do ordenamento jurídico brasileiro", promovido pelo Instituto dos Advogados do Rio Grande do Sul.

51 RINALDI, Stanislau. Crime organizado e poder político na Itália. In: Anais do III Congresso Nacional do Movimento do Ministério Público Democrático, Foz do Iguaçu, PR, 18-21 de março de 1997.
52 Art. 2o, V, da Lei $9.034 / 95$ e art. 33, I, da Lei 10.049/02.

${ }_{53}$ Art. 13 e 14 da Lei $9.807 / 99$ e art. $6^{\circ}$ da Lei 9.034/95.

54 Art. $7^{\circ}$ da Lei $9.034 / 95$.

55 Art. 9 o da Lei $9.034 / 95$.

56 Art. 10 da Lei $9.034 / 95$.

57 Art. 20 da Lei 9.034/95.

58 BORJA JIMÉNEZ, Emiliano. Globalización y Concepciones del Derecho Penal. Estudios Penales y Criminológicos, Santiago de Compostela, Espanha, USC, n. 29, p. 141-206, 2009, p. 163.

59 Alguns autores, como Jakobs, Baumann e Jescheck, entendem que o "homem de trás" (autor de escritório) é coautor, e não autor mediato. Outros, entendem que ele é um mero instigador. 